\title{
EDITORIAL
}

\section{The Challenges of Vasoformative Tumors of the Liver in Children}

\section{LOUIS P. DeHNeR*}

Lauren V. Ackerman Laboratory of Surgical Pathology, St. Louis Children's and Barnes-Jewish Hospital, Washington University Medical Center, Campus Box 8118, 660 South Euclid Avenue, St. Louis, MO 63110, USA

Received June 18, 2004; accepted June 18, 2004; Published online

Vasoformative neoplasms of the liver comprise a category of tumors that are encountered in children and adults alike, but the particular pathologic types or subtypes tend to segregate to one or the other age group [1,2]. For instance, the current issue of Pediatric and Developmental Pathology has a report of an angiosarcoma of the liver in a 5year-old girl who received a liver allograft but died from metastatic disease to the lungs slightly over 1 year later [3]. Angiosarcoma of the liver is one of those neoplasms, rare even in adults, which is extraordinarily uncommon in children [4-6]. It is estimated that only 10 to 20 new cases of hepatic angiosarcoma in all age groups are diagnosed each year in the United States [2]. One can compare this number with the 40 or so cases of hepatic angiosarcoma in children that have been reported to date in the literature (see Ref. 3, this issue, Table 1 , p. 531). Only $1 \%$ to $2 \%$ of all primary hepatic neoplasms of liver are angiosarcomas but constitute the most common primary sarcoma of the liver [7]. At one time, angiosarcoma of the liver was associated with thorotrast injections and, in the recent past, with industrial exposure to vinyl chloride [8]. In children, these tumors are sporadic in occurrence, without any established syndromic, genetic, or environmental associations.

*Corresponding author, e-mail: dehner@path.wustl.edu
The prognosis for hepatic angiosarcoma is dismal to the extent that long-term survival rates, regardless of age at diagnosis, are the subject of individual case studies [9-11].

My interest in vascular neoplasms of the liver in children was prompted by Kamel G. Ishak, MD, $\mathrm{PhD}$, who was kind enough more than 30 years ago to suggest this project and provided the cases. That study of 30 cases proposed the histopathologic criteria to differentiate between the so-called type 1 and type 2 infantile hemangioendotheliomas (IHs). Type 1 is characterized by diminutive but formed capillary-size vascular spaces accompanied by a fibrous stroma or separating individual cords of hepatocytes with or without associated small bile ducts [12]. Type 2 IH was recognized by its "more aggressive histologic pattern" characterized by "irregular budding and branching structures projecting into poorly formed vascular spaces." There were 5 infants with type $2 \mathrm{IH}$ who died of or with tumor; 1 of these cases was an 18-month-old female who died with metastatic disease to the lungs, bones, and brain, the classic distribution of metastatic angiosarcoma [12]. With the exception of 1 case in that study, all IHs had a type 1 or 2 histologic pattern. In a more recent review of IHs of the liver from the same institution, Selby et al. examined 91 cases, and approximately 90\% were diagnosed in 
the first 6 months of life [13]. The type 1 histologic pattern was exclusively observed in more than $70 \%$ of cases and included type 2 areas in another $20 \%$ of cases.

The current case of hepatic angiosarcoma is an instructive one because it demonstrates the problem of a small biopsy that may yield equivocal or inconclusive findings with an initial pathologic interpretation of "infantile hemangioendothelioma with atypical features" [3]. Inconclusive findings included nodules with slit-like vascular spaces, tufted profiles, and cytologically worrisome features. Conservative management of this patient did not prevent the inexorable progression of symptoms and signs with embolization and subsequent total hepatectomy and liver transplantation.

An important clue to the likelihood that this case of IH would represent the more serious angiosarcoma is the age at clinical presentation. As noted previously, IH of the liver is very uncommon after 1 year of age, whereas the average age of angiosarcoma of the liver in the 10 cases reported in children by Selby et al. was almost 4 years [6]. The small number of cases of putative type $2 \mathrm{IH}$ that my colleagues and I have seen in older children in our consultation practice has invariably presented a more aggressive clinical course than the more indolent type that is associated with type $1 \mathrm{IH}$ in the neonate or young infant [13-15]. Some investigators have advocated watchful waiting in those cases of type $1 \mathrm{IH}$ without hematologic or hemodynamic abnormalities because these tumors have the potential for spontaneous regression, such as hemangiomas in infants presenting elsewhere in the body. Based on several studies, it would appear that many of these hepatic tumors are examples of the so-called rapidly involuting congenital hemangioma with the characteristic immunohistochemical expression of glucose transporter-1 protein (GLUT1) by the endothelial cells [16-19]. The GLUT-1negative tumors are thought to represent arteriovenous malformations with a proliferating capillary component. One can appreciate the potential value of GLUT-1 immunostaining to distinguish the late presenting IH from some other vasoproliferative process. We remain doubtful of the potential of a type $1 \mathrm{IH}$ to progress to an angiosarcoma because there is little precedence for this phenomenon. More to the point, as this case demonstrates, is the focal nature of overtly malignant-appearing foci in an otherwise well-differentiated angiosarcoma. It is appreciated that an angiosarcoma can have more innocuous, less obviously malignant foci. If the vascular lesion in the liver of an older child is not a typical cavernous hemangioma or arteriovenous malformation, then complete surgical resection, if feasible, is probably advisable because of the infrequency of type $1 \mathrm{IH}$ in a child older than 2 years.

The topic of malignant vascular neoplasms of the liver is incomplete without an acknowledgment of the epithelioid hemangioendothelioma. This tumor type is regarded as a low-grade vascular malignancy, which is well documented in the second decade of life but is more commonly seen in adults $[20,21]$. The signet-ring cell-like features in a myxohyaline stroma may suggest metastatic carcinoma, especially in the presence of multiple hepatic lesions. Hepatic transplantation has been used with some success in the management of this tumor [22].

Some comments in closing are warranted about the differential diagnosis of liver neoplasms in the infant. We have seen our share of biopsies over the years, where the problems are ones of sampling and obscuring secondary changes, principally in the form of hemorrhage and fibrovascular reaction. When the latter histologic findings dominate the biopsy, it is difficult to be certain whether it is the stroma of an IH or mesenchymal hamartoma of the liver. We have found that a discussion with the pediatric radiologist is useful and clarifying in some instances. In contrast, hemorrhagic necrosis or hemorrhage without accompanying features such as dystrophic calcifications in the case of an IH usually defines the end of the diagnostic exercise in terms of the pathology. Hemorrhagic necrosis can be seen in the hepatoblastoma and the IH but uncommonly in the mesenchymal hamartoma.

\section{REFERENCES}

1. Ishak KG, Goodman ZD, Stocker JT. Tumors of the Liver, Intrahepatic Bile Ducts Washington DC: Armed Forces Institute of Pathology, 2001;81-93.

2. Mani H, Van Thiel DH. Mesenchymal tumors of the liver. Clin Liver Dis 2001;5:219-257. 
3. Dimashkieh HH, Ho JQ, Wyatt-Ashmead J, Collins MH. Pediatric hepatic angiosarcoma. A case report and review of the literature. Pediatr Dev Pathol 2004; 7:527-532.

4. Alt B, Hafez GR, Trigg M, Shahidi NT, Gilbert EF. Angiosarcoma of the liver and spleen in an infant. Pediatr Pathol 1985;4:331-339.

5. Awan S, Davenport M, Portmann B, Howard ER. Angiosarcoma of the liver in children. J Pediatr Surg 1996;31:1729-1732.

6. Selby DM, Stocker JT, Ishak KG. Angiosarcoma of the liver in childhood: a clinicopathologic and follow-up study of 10 cases. Pediatr Pathol 1992;12:485-498.

7. Anthony PP. Tumors and tumour-like lesions of the liver and biliary tract: aetiology, epidemiology and pathology. In: MacSween RNM, Bout AD, Portmann BC, Ishak KG, Scheuer PJ, Anthony PP, Eds. Pathology of the Liver. 4th ed. London: Churchill Livingstone, 2002; 750-752.

8. Kielhorn J, Melber C, Wahnschaffe U, Aitio A, Mangelsdorf I. Vinyl chloride: still a cause for concern. Environ Health Perspect 2000;108:579-588.

9. Gunawardena SW, Trautwein LM, Finegold MJ, Ogden AK. Hepatic angiosarcoma in a child: successful therapy with surgery and adjuvant chemotherapy. Med Pediatr Oncol 1997;28:139-143.

10. Timaran $\mathrm{CH}$, Grandas $\mathrm{OH}$, Bell JL. Hepatic angiosarcoma: long-term survival after complete surgical removal. Am Surg 2000;66:1153-1157.

11. Ozden I, Bilge O, Erkan M, Cevikbas U, Acarli K. Five years and 4 months of recurrence-free survival in hepatic angiosarcoma. J Hepatobiliary Pancreat Surg 2003;10:250-252.

12. Dehner LP, Ishak KG. Vascular tumors of the liver in infants and children: a study of 30 cases and review of the literature. Arch Pathol 1971;92:101-111.
13. Selby DM, Stocker JT, Waclawiw MA, Hitchcock CL, Ishak KG. Infantile hemangioendothelioma of the liver. Hepatology 1994;20:39-45.

14. Samuel M, Spitz L. Infantile hepatic hemangioendothelioma: the role of surgery. J Pediatr Surg 1995;30:14251429.

15. Iyer CP, Stanley P, Mahour GH. Hepatic hemangiomas in infants and children: a review of 30 cases. Am Surg 1996;62:356-360.

16. Berenguer B, Mulliken JB, Enjolras O. Rapidly involuting congenital hemangioma: clinical and histopathologic features. Pediatr Dev Pathol 2003;6:495-510.

17. Mulliken JB, Enjolras O. Congenital hemangiomas and infantile hemangioma: missing links. J Am Acad Dermatol 2004;50:875-882.

18. Prokurat A, Kluge P, Chrupek M, Kosciesza A, Rajszys P. Hemangioma of the liver in children: proliferating vascular tumor or congenital vascular malformation? Med Pediatr Oncol 2002;39:524-529.

19. Mo JQ, Dimashkieh HH, Bove KE. GLUT1 endothelial reactivity distinguishes hepatic infantile hemangioma from congenital hepatic vascular malformation with associated capillary proliferation. Hum Pathol 2004;35:200-209.

20. Makhlouf HR, Ishak KG, Goodman ZD. Epithelioid hemangioendothelioma of the liver: a clinicopathologic study of 137 cases. Cancer 1999;85:562-582.

21. Miller JH, Gillet PM, Hendry GM, Wallace WH. Congenital hemihypertrophy and epithelioid haemangioendothelioma in a 10-year-old boy: a case report. Pediatr Radiol 1999;29: 613-616.

22. Sharif K, English M, Ramani P. Management of hepatic epithelioid haemangio-endothelioma in children: what option? Br J Cancer 2004;90:1498-1501. 